\title{
Impact of Information Technology on Agriculture Development
}

\author{
Do Phi Hung
}

\begin{abstract}
Agriculture plays an essential role in the economic and social development of Vietnam. However, the agricultural sector faces many challenges, some of which arise from the Industrial Revolution 4.0, such as the application of Information Technology (IT). This paper illustrates the impacts of IT on agricultural development, online agricultural marketing, climate change adaptation, food security, and food safety in Vietnam. Research results show that for the agricultural sector to succeed in the 21st century, Vietnam must intensify its application of IT, make agricultural policy improvements, invest more in education, improve the qualification of receiving science and technology, and identify new agricultural production opportunities for the labour force.
\end{abstract}

Keywords: e-agriculture, agricultural information technology, food security, food safety.

\section{INTRODUCTION}

IT applied to agriculture, referred to as "e-agriculture," is developed and in use today in rural areas, and provides solutions to many challenges faced while working to enhance agricultural development. Just as in the context of communications, IT for e-agriculture includes device components, networks, mobile phones, services, and applications as well as existing telecommunication infrastructures, such as fixed telephones, televisions, radio, and satellite.

The benefits from IT for meeting the information needs of rural farmers include timely dissemination of agricultural information through online services, education and training, and e-commerce transaction platforms. Farmers can easily access valuable information through databases established by government or farming organisations, which facilitate an exchange of interaction between researchers, extension workers, traders, and farmers. Q \& A services can be available in the field to provide updated information to farmers, such as technical and production support packages, management skills, market information, weather forecasts, agricultural statistics, early warning signs of pests or diseases on livestock, natural disasters, and recommended measures to minimise losses. Compiling important market trends helps farmers find vital information they need, which can assist farmers better manage their farm economics. Finally, by participating in e-commerce, the rural farmer can have a direct link to producers, traders, retailers, and suppliers

Revised Manuscript Received on September 22, 2019

* Correspondence Author

Do Phi Hung, Faculty of Information Technology, Hochiminh City University of Foreign Languages - Information Technology (HUFLIT),

Hochiminh City, Vietnam. Email: dophihung@huflit.edu.vn
[1]-[4].

Rapid and timely dissemination of scientific and technological information is also important for farmers to improve income. Small and medium-sized enterprises use their resources more effectively to improve their competitiveness. With the expansion of agribusiness extension programs and consultancy services, commercial farms often need to leverage management technology and marketing strategies. Applying IT to agriculture can help solve food crises and contribute to the sustainable development of the country as populations grow, resources become exhausted, and extreme weather due to global climate change becomes more common.

\section{THE IMPACT OF IT ON AGRICULTURE IN VIETNAM}

\section{A. Online agricultural marketing}

Online agricultural marketing is an indispensable activity in the digital age. It provides a new opportunity for introducing farmers' products to the market while creating an advantage for medium-sized enterprises and small businesses in the field of agriculture to actively reach new customers by providing information towards long-term goals.

A prominent trend in online marketing is video advertising. Intuitive graphics enable the promotion and message transmission modern and easy to share through online channels with a potential for large numbers of users, such as YouTube and Facebook. Another important trend is seen in mobile marketing, which is predicted to become the primary approach as the number of people visiting websites through mobile devices continues to increase.

As illustrated in Fig. 1, web-based databases accessed via mobile devices enable farmers to know the prices of agricultural commodities available on the market. This assists them with decisions on where and when to bring a product to market, which offers high economic value. As such, IT provides useful tools for sharing trade information locally, nationally, and internationally. For example, with local and regional comparisons, the dissemination of agricultural information will help the development of both inside and outside the market. In e-commerce, the Internet directly connects manufacturers and consumers. With this opportunity, some farmers today are performing successful Internet marketing by creating and maintain websites to participate in e-commerce transactions, advertise, and trade their products [2], [3],[5]-[7]. 


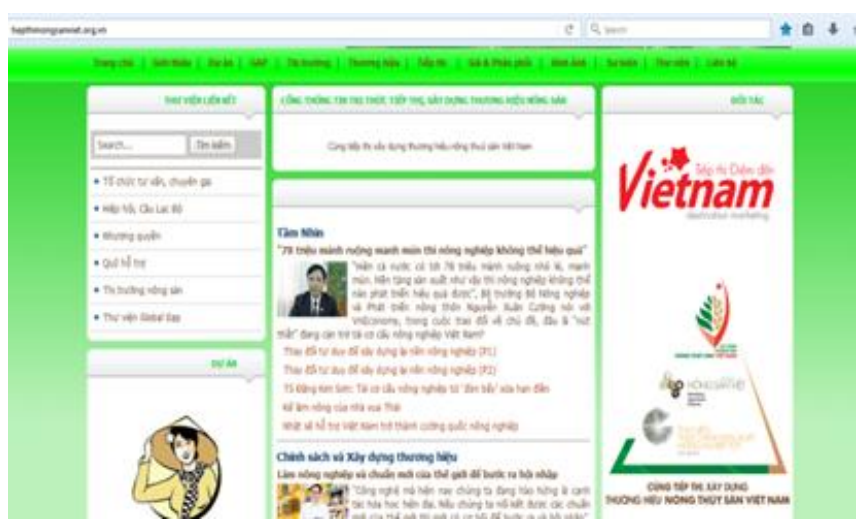

Fig. 1. A web interface for an agricultural database and marketing platform for farm produce.

\section{B. Food security and food safety}

Food security is a crucial process and is often incorporated with the national development strategy associated with the defence of a country. From the perspective of the United Nations, food security must ensure that food safety and nutrition are available as well as a timely supply of food at all times accessible by society. Any threat to food security can be a source of instability within the country, the region, and the world.

IT application in agriculture is one of the solutions to reduce food safety and hygiene problems. Unsafe food and hunger can occur at any time if access to information about food supply and safety is restricted or unpredictable. The most frequently mentioned solutions in food security and hygiene are nutrition education; establishing a community food bank; hands-on planning, budgeting, and smart shopping skills; online inventory system; The online community food support system provides information about services provided by civilian support organizations; Online food donation information system so that donors can know what food is most in demand [8],[9].

Traceability is a new trend in food production and distribution, and is closely related to food safety. Consumers want to know where the food they are using is raised or where they come from. The application of IT to food traceability is becoming increasingly popular with consumers. To provide consumers with safe agricultural products and ensure food consumption without worry, nowadays food information management systems in big cities like Ho Chi Minh, Hanoi, Da Nang has also implemented two-dimensional bar code technology to check and trace the origin of food through smart phones as seen in Fig. 2.

\section{Adapting to climate change}

Vietnam is a country severely affected by climate change and natural disasters. IT plays an important role in minimising the impacts of global climate change. Applications of IT for adapting to climate change include data collection through Remote Sensing (RSIS) or Geographic Information System (GIS) with valuable information for storing and analysis to be used as the basis for decision making [10]-[13].

Applying ICT to climate change can be performed locally with various tools providing analysis for different processes, which can be categorized into the following tasks.

Observation. This is an important initial stage to understand how climate change is occurring in a specified area (region/region/country) through data collection tools, such as remote-sensing technology and sensor-based networks. The data is stored in a digital data warehouse and shared with relevant agencies and organisations for implementing appropriate climate change adaptation strategies.

Planning and Analysis. Scientists and policymakers collaborate in data analysis, planning, and design of climate change adaptation strategies. IT facilitates the analysis of climate change scenarios through software simulations, decision support systems (DSS), and GIS to enable implementation of "if-then" scenarios of different issues on a multilateral basis

Implementation and management. Implementing and managing a climate change adaptation depends on multiple factors, such as the establishment of relevant departments and the scope of implementation. IT facilitates these processes through forecasting tools, early warning systems, and resource management systems.

Capacity building. IT can be leveraged to raise awareness and support through the Internet as well as provide training to combat climate change.

Data network. IT facilitates the creation, storage, processing, and collation of information related to climate change. The network infrastructure allows for the connection, knowledge sharing, and the development of partnerships at regional and global levels to address the challenges of climate change around the world.

Monitoring and evaluation. The final phase of adaptation includes monitoring and evaluation to ensure implementation initiatives are regular to achieve the goals identified during the planning phase. IT provides effective adaptation strategies through GIS technology that support monitoring and evaluation of ongoing efforts.

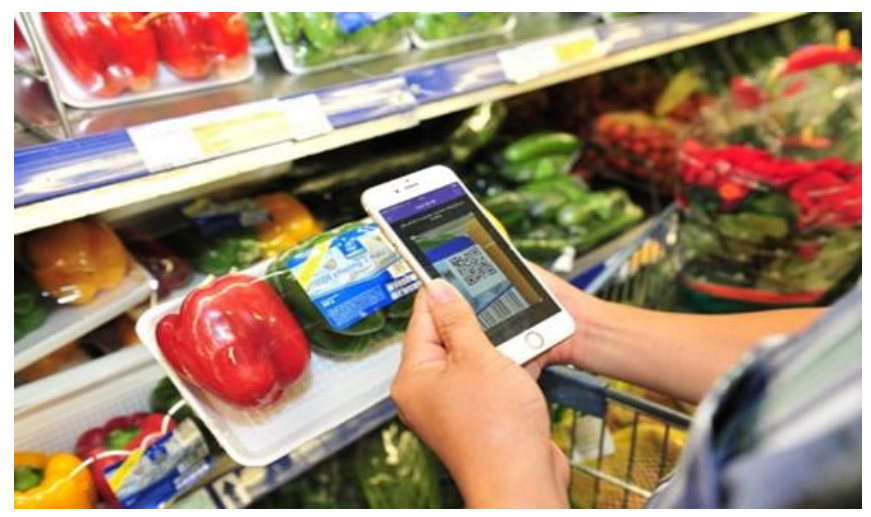

Fig. 2. The two-dimensional bar code used to scan produce for identification by a consumer. 


\section{BARRIERS TO AGRICULTURE}

IT is a core component in the successful development of agriculture. However, in Vietnam, the application of IT in agricultural production for farmers remains difficult and limited because the adoption of IT applications is new. Most agricultural labourers are aware of the technology available, and enterprises investing in high-tech agriculture continue to struggle due to a lack of capital resulting from large initial investments.

Policy impediments also make the investment in and application of IT in agricultural production unsynchronised. Science and technology initiatives have not promoted their role as a driving force to be leveraged for production and business. Enterprises continue to face many difficulties, and administrative procedures are cumbersome and complicated.

\section{CONCLUSION}

To provide a sustainable agriculture industry and develop the country into an agricultural power today, it is necessary to invest more in education to enhance the awareness for bringing science and technology and new agricultural thinking to the agricultural workforce.

Ministries and governmental branches should review and amend the system of legal documents related to IT application in agriculture as well as create favourable conditions for businesses and people to approach new policies. At the same time, Land Laws should be amended to solve difficulties in establishing large-scale agricultural production areas.

Colleges and universities involved in the field of agriculture and rural development must provide leadership in the high-tech agricultural field by preparing IT students with knowledge in this field. Young people will then enter into a career in agriculture bring with them the application of modern technology, which will create a sustainable and robust developmental foundation for agriculture in the future.

\section{REFERENCES}

1. Nakasone, Eduardo, Maximo Torero, and Bart Minten. "The power of information: The ICT revolution in agricultural development." Annu. Rev. Resour. Econ., 6.1: 533-550, 2014.

2. Dr. Sunil Phougat, Assistant Professor, "Applications of Information Technology in Agriculture Sector", Proceedings of National Conference on Innovative Trends in Computer Science Engineering (ITCSE-2015) held at BRCMCET, Bahal on 4th April 2015, 2015.

3. Aker, J. C., "Dial "A" for agriculture: a review of information and communication technologies for agricultural extension in developing countries", Agricultural Economics, 42(6), 631-647, 2011.

4. www.e-agriculture.org.

5. Tran, T.K., Phan, T.T.: Mining opinion targets and opinion words from online reviews. Int. J. Inf. Technol. 9(3), 239-249, 2017.

6. Tran, T.K., Phan, T.T., A hybrid approach for building a Vietnamese sentiment dictionary, J. Intell. Fuzzy Syst. 35(1), 967-978, 2018.

7. Tran, T.K., Phan, T.T., Towards a sentiment analysis model based on semantic relation analysis, Int. J. Synth. Emot. (IJSE) 9(2), 54-75, 2018.

8. Gupta, R., "Food Security and Safety using advanced Information and Communication Technologies (ICTs)", In Proceedings of the Second International Conference on Information and Communication Technology for Competitive Strategies, (p. 58). ACM, 2016.

9. Sala, S., The Role of Information and Communication Technologies for Community-Based Adaptation to Climate Change, FAO of The United Nation, Rome, Italy, 2010.
10. Singh, D., Piplani, D., Nar, S., Karthik, S., Sharma, R., \& Tiwari, A., "ICT platform for Climate Change Adaptation in agriculture", In Communication Systems and Networks (COMSNETS), 7th International Conference on (pp. 1-6). IEEE, 2015.

11. Upadhyay, A., and Arvind Bijalwan, "Climate change adaptation: services and role of information communication technology (ICT) in India." American Journal of Environmental Protection 4, no. 1 (2015): 70-74, 2015.

12. Asian Development Bank, "Technologies to Support Climate Change Adaptation in Developing Asia,” pp. 22-24, viewed 5 January 2017, Available from https://www.adb.org/sites/default/files/publication/149400/technologiesclimate-change adaptation.pdf, 2014.

13. OECD, Các chính sách nông nghiệp của Việt Nam 2015, Nhà xuất bản PECD, Paris, viewed 5 January 2017, Available from http://dx.doi.org/10.1787/9789264235151-en, 2015.

\section{AUTHORS PROFILE}

Do Phi Hung earned his M.S degree in Computer Engineering from International Univerisity, Ho Chi Minh City. He is a lecturer at Huflit. His research is situated in the field of Technology \& Innovation, with aspecial focus on international technology transfer. 